\title{
Prevalence of Glycemic Control in the Elderly Adult: A Retrospective Study
}

\author{
Hector Eloy Tamez-Perez ${ }^{1,2 *}$, Enrique Delgadillo-Esteban ${ }^{1}$, Alejandra Lorena Tamez-Peña ${ }^{1}$ and David Soni- \\ Duque $^{2}$
}

${ }^{1}$ Facultad de Medicina y Hospital Universitario “Dr. Jose Eleuterio Gonzalez”, Universidad Autonoma de Nuevo Leon, México

${ }^{2}$ Hospital Clínica NOVA, México

Submission: March 27, 2019; Published: April 18, 2019

*Corresponding author: Hector Eloy Tamez-Perez, Subdirección de Investigación, Sotano Edificio CRIDS, Calle Dr. Eduardo Aguirre Pequeño s/n Colonia Mitras Centro, C.P. 64460, Monterrey, N.L., México

\section{Abstract}

Background: The prevalence of type 2 diabetes has rapidly increased and become a serious public health problem all over the world.

Objective: The aim of this study was to determine the prevalence of adequate glycemic control in a population over 65 years of age.

Design: This was a cross-sectional retrospective study.

Setting: Nova Hospital Clinical Unit in Monterrey, Mexico. A private hospital-clinic.

Participants: A total of 1149 patients over 65 years of age with type 2 diabetes mellitus

Measurements: Medical records of patients from an electronic database were analyzed. The inclusion criteria were patients over 65 years of age with type 2 diabetes mellitus. Patients with diabetic ketoacidosis, hyperosmolar hyperglycemic state or poor treatment compliance were excluded. The statistical analysis was performed using the R-project for statistical computing v 3.3 .3 . A p <0.05 was considered statistically significant.

Results: Median age was 75 (IQ 70.81) years. Of the study population, 600 (52.22\%; 95\% CI [49.33, 55.1]) achieved glycemic control with an $\mathrm{HbA1c}<7 \%$. An insulin requirement was necessary in 172 (14.97\% 95\% CI [13.02, 17.05]) patients.

Conclusion: The prevalence of glycemic control using a strict criterion in our setting was greater than that reported in the literature. Further studies are needed to estimate the prevalence of glycemic control with current definitions in elderly adults.

Keywords: Diabetes mellitus; Aged adult; Glycemia; Type 2 diabetes; Public health; Health and nutrition; Geriatric syndromes; Polypharmacy; Urinary incontinence; Cognitive impairment; Hospitalization; Muscle mass; Hypertension; Coronary artery disease; Cerebral infarction

\section{Introduction}

The prevalence of type 2 diabetes (T2DM) has rapidly increased and become a serious public health problem all over the world [1]. (T2DM) is a chronic degenerative disease with a prevalence of $9.4 \%$ in 2016 according to the National Survey of Health and Nutrition Midway 2016 in Mexico [2] but it increases in up to one in four elderly adults over 65 years of age and aging of the general population has been documented as an etiological factor [3]. Elderly adults with (T2DM) have an increased risk of premature death, functional disability, accelerated loss of muscle mass and diseases such as hypertension, coronary artery disease and cerebral infarction. They can also present geriatric syndromes, polypharmacy, urinary incontinence, cognitive impairment and a greater risk of hospitalization [4].
Current international recommendations for these patients include multidisciplinary management to reach glycemic goals by $\mathrm{HbA} 1 \mathrm{C}$, which is achieved in $25 \%$ to $41 \%$ of cases and always at the expense of serious adverse effects of treatment [5].

Therefore, the objective of this study was to determine the prevalence of adequate glycemic control in a population over 65 years and to assess the efficacy of different antidiabetic drugs in a private clinic in northern Mexico.

\section{Materials and Methods}

This was a cross-sectional retrospective study of medical records from an electronic database of the Nova Clinic and Hospital Unit in Monterrey, Mexico. The research was performed 


\section{Current Research in Diabetes \& Obesity Journal}

during 2018. The inclusion criteria were patients with (T2DM) over 65 years of age. Exclusion criteria were patients with acute complications such as ketoacidosis and hyperosmolar hyperglycemic syndrome, type 1 diabetes and a hospitalization in the last six months. Demographic variables such as sex, age, antidiabetic treatment, and comorbidities were evaluated. Adequate glycemic control was defined as an HbA1c less than 7\%; the same criteria was used for younger patients [5]. The protocol was approved by the institutional ethics and research committee.

Data were presented as descriptive statistics using central tendency measures, dispersion, and percentages. To evaluate differences in proportion, Pearson's chi square test or Fisher's exact test was used as necessary. Confidence intervals were

Table 1: Efficacy of antidiabetic drugs in elderly adults.

\begin{tabular}{|c|c|c|c|c|c|}
\hline Drug & HbA1c $<7 \%$ n (\%) & HbA1c $>7 \%$ n (\%) & $\mathbf{p}$ & OR & $95 \% \mathrm{CI}$ \\
\hline Dapagliflozin & $20(24.1)$ & $63(75.9)$ & $<0.001^{* *}$ & 0.27 & {$[0.15,0.45]$} \\
\hline Canagliflozin & 7 (28) & $18(72)$ & $<0.05^{*}$ & 0.35 & {$[0.12,0.88]$} \\
\hline Insulin & 55 (31.98) & $117(68.02)$ & $<0.001^{* *}$ & 0.37 & {$[0.26,0.53]$} \\
\hline Metformin & $445(57.64)$ & $327(42.36)$ & $<0.001^{* *}$ & 1.95 & {$[1.51,2.52]$} \\
\hline Glimepiride & $4(25)$ & $12(75)$ & 0.052 & 0.3 & {$[0.07,1]$} \\
\hline Glipizide & 13 (39.39) & $20(60.61)$ & 0.186 & 0.59 & {$[0.27,1.25]$} \\
\hline Saxagliptin & $161(50.31)$ & 159 (49.69) & 0.46 & 0.9 & {$[0.69,1.17]$} \\
\hline Acarbose & $28(47.46)$ & $31(52.54)$ & 0.536 & 0.82 & {$[0.47,1.43]$} \\
\hline Pioglitazone & $45(62.5)$ & $27(37.5)$ & 0.0925 & 1.57 & {$[0.94,2.67]$} \\
\hline
\end{tabular}

*Statistically significant result; **Highly significant result.

The use of insulin was documented in 172 patients (14.97\%, $95 \%$ CI $[13.02,17.05])$ with $31.97 \%$ (95\% CI $[25.45,39.28])$ achieving the glycemic goal. No patients were treated exclusively with non-pharmacological measures. In the oral drug group, the greatest proportion was treated with metformin $(772 ; 57.64 \%$, 95\% CI [54.12, 61.08]), with this being associated with better glycemic control. The data from each group are shown in Table 1.

LDL cholesterol levels were $<100 \mathrm{mg} / \mathrm{dL}$ in 591 patients (51.4\%) with the use of statins. The platelet aggregation inhibitor, acetylsalicylic acid (ASA) $100 \mathrm{mg}$ was prescribed in 573 patients (49.8\%). An annual ophthalmologic assessment was carried out in 521 patients $(45.3 \%)$.

\section{Discussion}

In this study the proportion of patients over 65 years of age with T2DM was almost 40\%, predominating in more than half of those between 65 and 75 years. This finding is greater than that previously reported where a proportion of $21.6 \%$ was found [7]. We found adequate global glycemic control in $52.21 \%$ of patients. If we consider a more flexible $\mathrm{HbA} 1 \mathrm{c}$ range between $7-8 \%$ as has been described in other International publications and guidelines, this proportion would be greater [7-9]. Hypoglycemia is one of the most important adverse factors in the metabolic control of this group of patients and its absence reduces the risk of cognitive disorders and other adverse events of morbidity and mortality; calculated using the Agresti et al. [6] method. A p $<0.05$ (twotailed) was considered statistically significant. All data were analyzed with the R Project for Statistical Computing v 3.3.3.

\section{Results}

The total number of patients with (T2DM) was 2946; of these, 1149 (39.1\%) met the inclusion criteria. According to age range, groups were distributed in the following manner: 65-75 years, $52.30 \%$ (95\% CI [49.41, 55.18]); 76-85 years, 38.03\% (95\% CI [35.27, 40.87]); and >85 years, 9.66\% (95\% CI [8.08 11.51]). With regard to gender 535 (46.56\%) patients were men and 614 (53.43\%) were women. Six hundred patients $(52.22 \%, 95 \% \mathrm{CI}$ $[49.33,55.1])$ reached the glycemic goal; an HbA1c level of $9 \%$ was found in $341(18.9 \%)$. therefore, we believe that the current recommendations for this group of patients should be less strict (in contrast to the definition used in our group), reasonably relaxed, and individualized to each patient. A consensus from American and European societies of diabetes recommends patient-oriented treatment [10]. Other studies and recommendations have reported elevated morbidity and mortality with intensive therapeutic goals $[11,12]$.

We found that the use of metformin was associated with better glycemic control. This finding could be explained by a multifactorial mechanism related to the anti-hyperglycemic activity of this drug and treatment tolerance [13]. Similar to findings reported in other publications, patients with insulin requirements have less glycemic control than those who take oral drugs or non-insulin injectables. This is associated with the evolution of the disease, its physiopathology, physician and patient inertia, etc [9-11,14]. The most recent drugs introduced for treatment of T2DM in our setting are SGLT2 inhibitors. In the Nova clinic we have dapagliflozin; however, glycemic control has been suboptimal and similar to finding could be due to inefficient assessment of candidates for this drug.

Treatment of other cardiovascular risk factors, for example, with statins, occurred in $50 \%$ of cases. We know that in primary prevention, there is controversy regarding this recommendation; a previous real-world study carried out by our group [15]. This 


\section{Current Research in Diabetes \& Obesity Journal}

however, in secondary prevention it is a universal indication [16]. This is also true in primary prevention with platelet aggregation inhibitors in patients with T2DM [17]. These measures should be implemented according to hierarchy and desirable goals [10]. Universal recommendations for the prevention of microvascular complications such as the assessment of albuminuria were not reported and the percentage of patients sent for ophthalmologic evaluation was low, considering this an area of opportunity for optimizing service.

There are cohort studies in Mexico that analyze cardiovascular morbidity and mortality and its treatment in ambulatory patients [18] and one publication from our group regarding hospital patients [19]; also, genetic studies that do not provide information on the elevated prevalence of this pathology in our setting [20].

The strength of our study is that it is an evaluation of a group of patients consulted in a private clinic in Northern Mexico whose primary contact is an internal medicine specialist. The limitations of our study include not having a report of other macrovascular and microvascular risk factors such as smoking, hypertension, renal function, ophthalmologic evaluation, etc. In addition, adverse effects associated with therapy in patients over 65 years of age, for example, hypoglycemia, which is a factor associated with greater mortality in several studies $[10,16,17]$, were not determined. Comorbidities, polypharmacy, treatment compliance and a reduction in $\mathrm{HbA1c}$ patients who did not achieve goals.

We must familiarize ourselves with independent medical education and carry out precision medicine. In T2DM, the selection of treatment must be specific for each patient and include knowledge of potential adverse effects, the required reduction of $\mathrm{HbA1C}$, the patient's age, the conditions of concomitant drugs, and the patient's preferences, since the cost is financed by an institutional health system.

\section{Conclusion}

The prevalence of T2DM in the geriatric patient is greater than that published. Strict glycemic control is achieved in approximately half of the patients, in who we should adjust our goals to international recommendations, putting into context control versus risks. There are areas of opportunity in nonpharmacological recommendations, comorbidities, and the prevention of micro and macrovascular complications.

\section{Acknowledgements}

We thank Sergio Lozano-Rodriguez, M.D. for his help in translating the manuscript.

\section{Funding}

This study did not receive funding from any public, commercial or nongovernmental agency.

\section{References}

1. Bommer C, Heesemann E, Sagalova V, Manne-Goehler J, Atun R, et al. (2017) The global economic burden of diabetes in adults aged 20-79 years: a cost-of-illness study. Lancet Diabetes Endocrinol 5(6): 423 430.

2. Hernández M, Rivera J, Shamah T (2016) Encuesta Nacional de Salud y Nutrición de Medio Camino 2016. Instituto Nacional de Salud Pública: Cuernavaca, Mexico.

3. (2011) National diabetes fact sheet: national estimates and general information on diabetes and prediabetes in the United States, 2011. In. Atlanta, GA: U.S. Department of Health and Human Services, Centers for Disease Control and Prevention.

4. Yang Y, Hu X, Zhang Q, Zou R (2016) Diabetes mellitus and risk of falls in older adults: a systematic review and meta-analysis. Age Ageing 45(6): 761-767.

5. (2018) Glycemic targets: standards of medical care in diabetes-2018. Diabetes Care 41(1): S55-S64.

6. Agresti A, Coull BA (1998) Approximate is better than "exact" for interval estimation of binomial proportions. Am Stat 52(2): 119-126.

7. Arnold SV, Lipska KJ, Wang J, Seman L, Mehta SN, et al. (2018) Use of Intensive Glycemic Management in Older Adults with Diabetes Mellitus. J Am Geriatr Soc 66(6): 1190-1194.

8. Sugimoto T, Toba K, Sakurai T (2018) Status of glycemic control in elderly patients with cognitive impairment treated by general practitioners relative to the glycemic targets recommended for elderly patients by the Japan Diabetes Society/Japan Geriatrics Society Joint Committee: A retrospective analysis. J Diabetes Investig 9(5): 12301232.

9. Lubart E, Segal R, Wainstein J, Marinov G, Yarovoy A, et al. (2014) Evaluation of an intra-institutional diabetes disease management program for the glycemic control of elderly long-term care diabetic patients. Geriatr Gerontol Int 14(2): 341-345.

10. Davies MJ, D’Alessio DA, Fradkin J, Kernan WN, Mathieu C, et al. (2018) Management of hyperglycaemia in type 2 diabetes, 2018. A consensus report by the American Diabetes Association (ADA) and the European Association for the Study of Diabetes (EASD). Diabetologia 61(12): 2461-2498.

11. Arnold LW, Wang Z (2014) The HbA1c and all-cause mortality relationship in patients with type 2 diabetes is J-shaped: a metaanalysis of observational studies. Rev Diabet Stud 11(2): 138-152.

12. Pacheco J (2018) ¿ Debe el tratamiento intensivo de la diabetes mellitus tipo 2 ser un indicador de actividad de la atención primaria? Rev méd Chile 146(9): 1086-1086.

13. Solymar M, Ivic I, Poto L, Hegyi P, Garami A, et al. (2018) Metformin induces significant reduction of body weight, total cholesterol and LDL levels in the elderly - A meta-analysis. PloS one 13(11): e0207947.

14. Takao T, Matsuyama Y, Yanagisawa H, Kikuchi M, Kawazu S (2014) Association between $\mathrm{HbA1c}$ variability and mortality in patients with type 2 diabetes. J Diabetes Complications 28(4): 494-499.

15. Tamez-Perez HE, Delgadillo-Esteban E, Soni-Duque D, HernandezCoria MI, Tamez-Pena AL (2017) SGLT2 inhibitors as add on therapy in type 2 diabetes: a real-world study. J Diabetes Metab Disord 16: 27.

16. Li T, Wan X, Ma J, Wu B (2018) Cost-Effectiveness of Primary Prevention with Statin Treatment for Chinese Patients with Type 2 Diabetes. Adv Ther 35(12): 2214-2223.

17. Bowman L, Mafham M, Wallendszus K, Stevens W, Buck G, et al. (2018) Effects of Aspirin for Primary Prevention in Persons with Diabetes Mellitus. N Engl J Med 379(16): 1529-1539.

18. Alegre-Diaz J, Herrington W, Lopez-Cervantes M (2016) Diabetes and Cause-Specific Mortality in Mexico City. N Engl J Med 375(20): 19611971. 


\section{Current Research in Diabetes \& Obesity Journal}

19. Gutiérrez-Hermosillo H, de León-González ED, Pérez-Cortez P, CobosAguilar H, Gutiérrez-Hermosillo V (2012) Prevalencia de diabetes mellitus de tipo 2 y factores asociados en la población geriátrica de un hospital general del norte de México. Gac Med Mex 148(1): 14-18.
20. Totomoch-Serra A, Munoz ML, Burgueno J, Revilla-Monsalve MC, DiazBadillo A (2018) Association of common polymorphisms in the VEGFA and SIRT1 genes with type 2 diabetes-related traits in Mexicans. Arch Med Sci 14(6): 1361-1373.

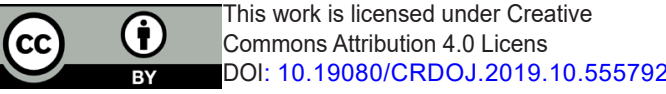

Your next submission with Juniper Publishers
will reach you the below assets
- Quality Editorial service
- Swift Peer Review
- Reprints availability
- E-prints Service
- Manuscript Podcast for convenient understanding
- Global attainment for your research
- Manuscript accessibility in different formats
( Pdf, E-pub, Full Text, Audio)
- Unceasing customer service
Track the below URL for one-step submission
https://juniperpublishers.com/online-submission.php

